\title{
Fuel Consumption Analysis and Optimization Based on Minitab
}

\author{
Yu Qian ${ }^{1, ~ a ~}$, Ziyuan Mao ${ }^{1, b}$ \\ ${ }^{1}$ Civil Aviation Flight University of China, Guanghan Sichuan 618307, China \\ aqianyucafuc@126.com, bm15283830068@163.com
}

Keywords: Fuel consumption, fuel Optimization, Minitab.

Abstract. Excess fuel on board reduces payload and increases fuel burn. In order to reduce fuel consumption, the optimization of fuel policy is one of its technical. In this paper, a statistical method to fuel policy optimization with Minitab is studied. The QAR and flight plan data are used to analysis. As an example, the flight's data from Beijing to Bangkok is analyzed with MINTAB. The results of data analysis show that the fuel policy can be optimized by historical data analysis and statistical method.

\section{Introduction}

At present, the problem of energy saving is more and more important. Excess fuel on board reduces payload and increases fuel burn. The total amount of fuel carried aboard an airplane is determined by the distance the airplane is to fly, requirements for reserve fuel to meet unexpected situations, and considerations of safety and economics. ICAO Annex 6 "Part I-International Commercial Air Transport-Aeroplanes" stipulates that "4.3.6.1 An aeroplane shall carry a sufficient amount of usable fuel to complete the planned flight safely and to allow for deviations from the planned operation." CCAR-121 also have the same stipulates. The fuel carried aboard is also determined by the fuel policy in regulations of civil aviation authorities and the airlines. Regulations in each country specify the amount of fuel to be carried, and airlines base their fuel policy on those national regulations. Chinese operators established their fuel policy to satisfy CAAC regulation CCAR 121 fuel requirements. The latest version of CCAR 121 is R5, issued in 2017. In CCAR 121 R5, the CAAC allowed that "the operator may, based on the results of a specific safety risk assessment conducted by the operator which demonstrates how an equivalent level of safety will be maintained, approve variations to the pre-flight fuel calculation of fuel with different/optimized fuel policy."

\section{Fuel policy in CCAR 121 R5}

CCAR 121R5.121.657 Fuel requirements: An aeroplane shall carry a sufficient amount of usable fuel to complete the planned flight safely and to allow for deviations from the planned operation. The pre-flight calculation of usable fuel required shall include in table 1 for each operator. 
Table 1. The fuel requirements in CCAR $121 \mathrm{R} 5$

\begin{tabular}{|c|c|}
\hline Fuel & Calculation method \\
\hline Taxi fuel & $\begin{array}{l}\text { which shall be the amount of fuel expected to be consumed before take-off, taking into account } \\
\text { local conditions at the departure aerodrome and auxiliary power unit (APU) fuel consumption }\end{array}$ \\
\hline Trip fuel & $\begin{array}{l}\text { which shall be the amount of fuel required to enable the aeroplane to fly from take-off, or the } \\
\text { point of inflight re-planning, until landing at the destination aerodrome taking into account the } \\
\text { operating conditions }\end{array}$ \\
\hline $\begin{array}{l}\text { Contingency } \\
\text { fuel }\end{array}$ & which shall be the amount of fuel required to compensate for unforeseen factors \\
\hline $\begin{array}{l}\text { Destination } \\
\text { alternate fuel }\end{array}$ & $\begin{array}{l}\text { the amount of fuel required to enable the aeroplane to: } \\
\text { i) perform a missed approach at the destination aerodrome; } \\
\text { ii) climb to the expected cruising altitude; } \\
\text { iii) fly the expected routing; } \\
\text { iv) descend to the point where the expected approach is initiated; and } \\
\text { v) conduct the approach and landing at the farthest destination alternate aerodrome. }\end{array}$ \\
\hline $\begin{array}{l}\text { Final reserve } \\
\text { fuel }\end{array}$ & $\begin{array}{l}\text { which shall be the amount of fuel calculated using the estimated mass on arrival at the } \\
\text { destination alternate aerodrome, or the destination aerodrome when no destination alternate } \\
\text { aerodrome is required }\end{array}$ \\
\hline $\begin{array}{l}\text { Discretionary } \\
\text { fuel }\end{array}$ & which shall be the extra amount of fuel to be carried at the discretion of the operator \\
\hline
\end{tabular}

The most important of CCAR 121 R5 is that the CAAC allowed the operator optimize their fuel policy with operation data in CCAR 121.663(C). In this paper, we focus on contingency fuel policy optimization.

Contingency fuel. Which shall be the amount of fuel required to compensate for unforeseen factors. It shall be ten per cent of the planned trip fuel or of the fuel required from the point of in-flight re-planning based on the consumption rate used to plan the trip fuel but, in any case, shall not be lower than the amount required to fly for 15 minutes at holding speed at $450 \mathrm{~m}(1500 \mathrm{ft})$ above the destination aerodrome in standard conditions. Unforeseen factors are those which could have an influence on the fuel consumption to the destination aerodrome, such as deviations of an individual aeroplane from the expected fuel consumption data, deviations from forecast meteorological conditions, extended delays and deviations from planned routings and/or cruising levels.

\section{Fuel consumption data analysis and optimization}

The data analysis is difference in fuel burn and fuel plan. We investigated actual fuel burn data in order to establish a reasonable quantity as standard contingency fuel. We compared the actual fuel burn with the planned fuel burn. The result of this comparison is discussed in the following paragraphs.

The Fuel burn difference. We calculated burn off fuel from block-out to block-in in the flight plan as follows:

Planned fuel burn $=$ taxi fuel + trip fuel

Actual fuel burn is calculated as follows from our flight operations database:

Actual fuel burn = onboard fuel-remaining fuel

We compared the actual fuel burned with the planned fuel burned in the following equation and then displayed the difference as a percentage to eliminate the influence of aircraft size, fuel consumption rate, and aircraft deterioration:

Fuel burn difference $=[($ actual fuel burn - plan burn off fuel $) /($ plan burn off fuel $)] \times 100$

Normality test With Anderson-Darling Method. Many statistical procedures rely on population normality, and using a normality test to determine whether to reject this assumption can be an important step in the analysis. The null hypothesis for a normality test states that the population in normal. The alternative hypothesis states that the population is no normal. Anderson-Darling test 
method compares the empirical cumulative distribution function of the sample data with the distribution expected if the data were normal. If this observed difference is sufficiently large, the test will reject the null hypothesis of population normality.

Statistical inference. Statistical inference makes propositions about a population, using data drawn from the population with some form of sampling. Given a hypothesis about a population, for which we wish to draw inferences, statistical inference consists of (first) selecting a statistical model of the process that generates the data and (second) deducing propositions from the model. The conclusion of a statistical inference is a statistical proposition.Some common forms of statistical proposition are the following:a point estimate, an interval estimate, a credible interval, rejection of a hypothesis,clustering or classification of data points into groups.

In this paper, we would define an acceptability value for calculating $x$ valule, showing in Fig.1. For different acceptability value, $x$ is different.

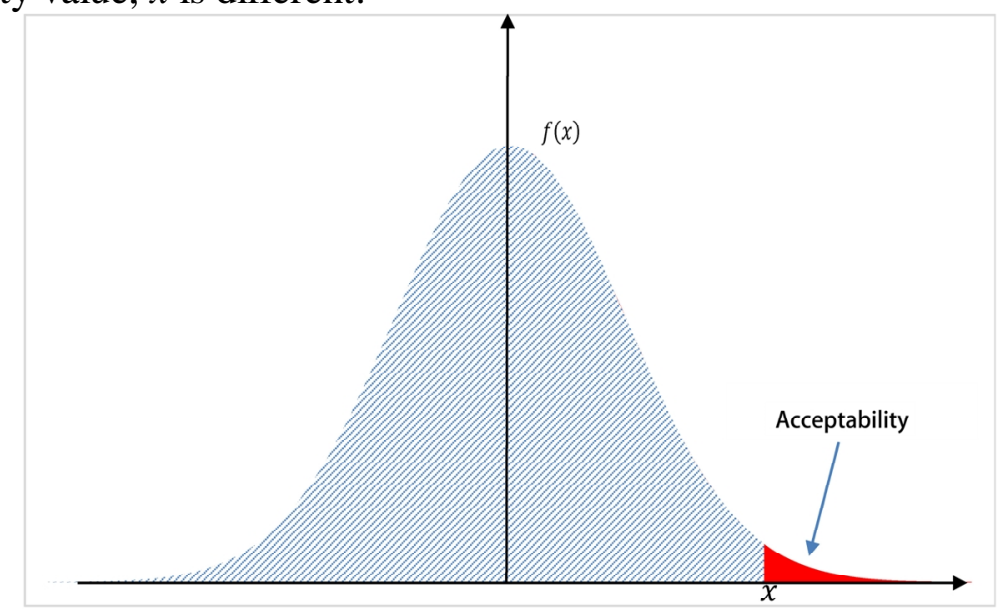

Fig. 1 Define the acceptability value

Minitab tool. Minitab is a statistics package developed at the Pennsylvania State University by researchers Barbara F. Ryan, Thomas A. Ryan, Jr., and Brian L. Joiner in 1972. It began as a light version of OMNITAB, a statistical analysis program by NIST; the documentation for OMNITAB was last published 1986, and there has been no significant development since then. It is a tool for managing Six Sigma and Lean Manufacturing.

\section{Fuel consumption data analysis example}

For analysis fuel consumption data, we collecting the QAR and flight plan data from airlines. As a example, we shows a flight from Beijing(ZBAA) to Bangkok(VTBD) and back wiht Boeing 737-800. There are 128 flight data from ZBAA to VTBD, and 127 flight data from VTBD to ZBAA. The statistical information for the data are showing in talble 2.

Table 2. The statistical information for ZBAA-VTBD flight

\begin{tabular}{|c|c|c|c|c|c|c|}
\hline Flight & $\begin{array}{c}\text { No.of } \\
\text { flight }\end{array}$ & $\begin{array}{c}\text { Mean of plan } \\
\text { fuel }(\mathrm{kg})\end{array}$ & $\begin{array}{c}\text { Mean of burn } \\
\text { fuel }(\mathrm{kg})\end{array}$ & $\begin{array}{c}\text { Mean of } \\
\text { contingency } \\
\text { fuel }(\mathrm{kg})\end{array}$ & $\begin{array}{c}\text { Mean of burn } \\
\text { difference }(\mathrm{kg})\end{array}$ & $\begin{array}{c}\text { Standard } \\
\text { deviation }\end{array}$ \\
\hline ZBAA-VTBD & 128 & 14203 & 13536 & 1287 & -0.0470 & 0.02673 \\
\hline VTBD-ZBAA & 127 & 12977 & 12603 & 1163 & -0.0463 & 0.02490 \\
\hline
\end{tabular}

Normality test with Anderson-Darling method information are showing in fig.2, and fig.3 shows the summarized statistical information. As showing in Fig. 2 or Fig.3, P-value is 0.253, it is greater than 0.05 , the fuel consumption difference data for ZBAA-VTBD is normality. 


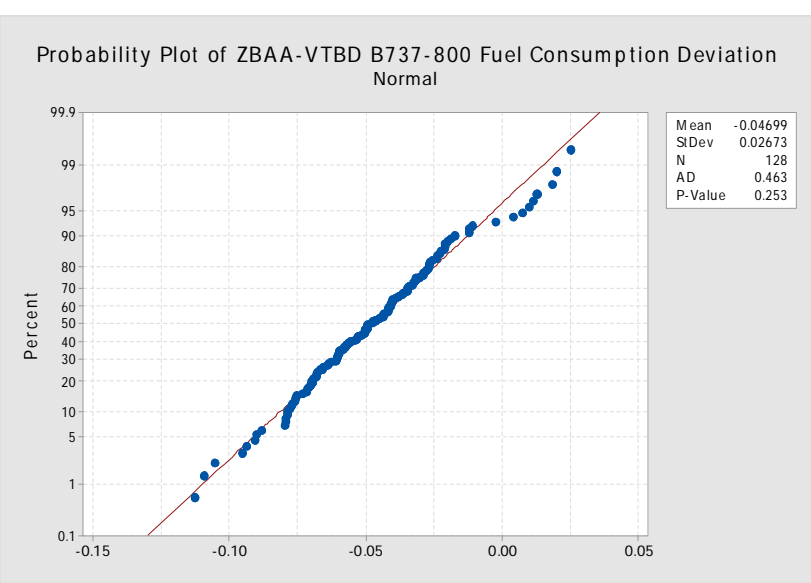

Fig. 2 Fuel Consumption Deviation Data Normality Test

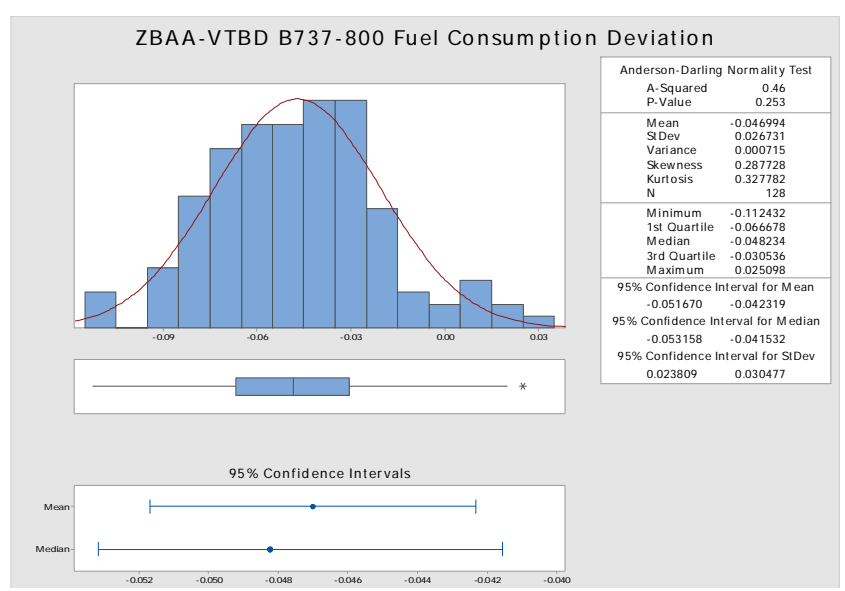

Fig. 3 Fuel Deviation Data summarized information

Fig. 4 is I-MR chart for fuel consumption deviation data for ZBAA-VTBD. Plots individual observations (I chart) and moving ranges (MR chart) over time for variables data. Use this combination chart to monitor process center and variation when it is difficult or impossible to group measurements into subgroups. Fig 5 is the histogram of the flight data.

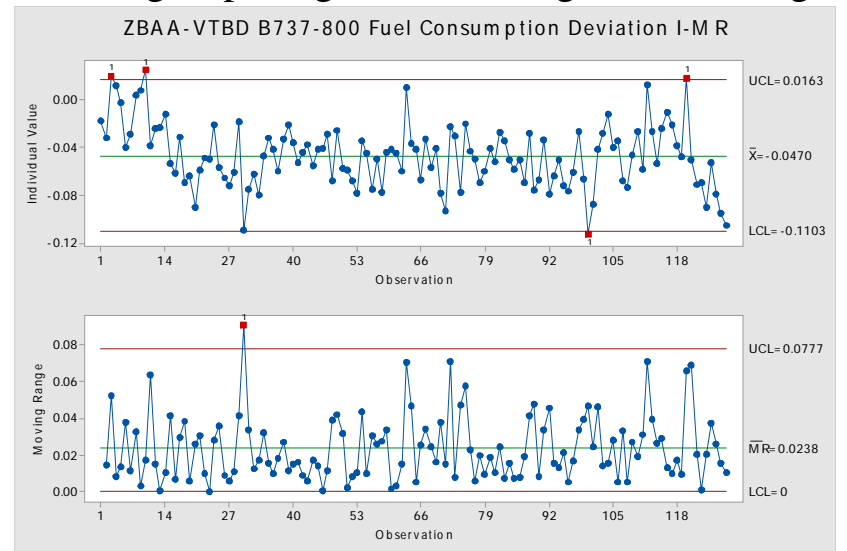

Fig. 4 I-MR chart for Fuel Consumption Deviation Data

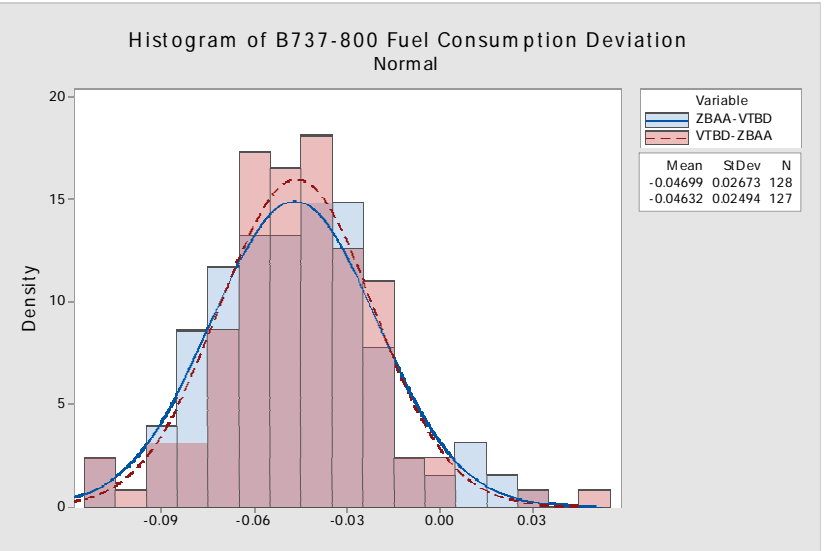

Fig. 5 Histogram of Fuel Deviation Data

In this example, the fuel consumption deviation data are normality. With normality data, it is easy to calculating the $\mathrm{x}$ value with different acceptability. In this study, we define two acceptability value as $1 \%$ and $3 \sigma$. The results are showing in table 3 as following.

Table 3. The statistical inference for ZBAA-VTBD flight

\begin{tabular}{|c|c|c|c|c|c|c|}
\hline Flight & $\begin{array}{c}\text { No.of } \\
\text { flight }\end{array}$ & $\begin{array}{c}\text { Mean of burn } \\
\text { difference }(\mathrm{kg})\end{array}$ & $\begin{array}{c}\text { Standard } \\
\text { deviation }\end{array}$ & $\begin{array}{c}\text { Normality } \\
\text { Test }\end{array}$ & $\begin{array}{c}\text { acceptability } \\
\text { value } 1 \%\end{array}$ & $\begin{array}{c}\text { acceptability } \\
\text { value } 3 \sigma\end{array}$ \\
\hline ZBAA-VTBD & 128 & -0.0470 & 0.02673 & Yes & 0.02 & 0.04 \\
\hline VTBD-ZBAA & 127 & -0.0463 & 0.02490 & Yes & 0.02 & 0.03 \\
\hline
\end{tabular}

The number of $x$ value is very useful for airline fuel policy optimization. This data is an important support for the application of different fuel policies to CAAC.

\section{Conclusions}

1) The airlines fuel policy can be optimized by historical data analysis and statistical method. As an example, this paper used ZBAA-VTBD QAR and flight plan data to calculate the fuel consumption deviation. The data anlysis with statistical method statistical inference is the basis of fule policy optimization.

2) MINTAB can easily anlysis the data of normal distribution, and the best way to anlysis non normal distribution data is programming. 


\section{References}

[1] Takashi Kondo. Fuel Conservation-Reserve Fuel Optimization. 2005 Boeing Performance and Flight Operations Engineering Conference.

[2] ICAO Annex 6. Operation of Aircraft Part I-International Commercial Air Transport-Aeroplanes. Tenth Edition, July 2016.

[3] ICAO Doc 9976.Flight Planning and Fuel Management (FPFM) Manual. First Edition-2015.

[4] EASA regulations. Part- CAT.OP.MPA.150 Fuel policy

[5] FAA Notice. OpSpec B343. Performance-Based Contingency Fuel Requirements for Flag Operations. N 8900.383 